\title{
Mechanisms of the CDK4/6 inhibitor palbociclib (PD 0332991) and its future application in cancer treatment (Review)
}

\author{
MINGHUI LIU ${ }^{1}$, HONGYU LIU ${ }^{2}$ and JUN CHEN ${ }^{1,2}$ \\ ${ }^{1}$ Department of Lung Cancer Surgery, ${ }^{2}$ Tianjin Key Laboratory of Lung Cancer Metastasis and Tumor Microenvironment, \\ Tianjin Lung Cancer Institute, Tianjin Medical University General Hospital, Heping, Tianjin 300052, P.R. China
}

Received September 14, 2017; Accepted January 10, 2018

DOI: 10.3892/or.2018.6221

\begin{abstract}
An uncontrolled cell cycle is an obvious marker of tumor cells. The G1-S phase is an important restriction point in the normal cell cycle, but in cancer cells the restriction function is reduced, leading to uncontrolled cell proliferation. Two cyclin-dependent kinases (CDKs), CDK4 and CDK6, play a crucial role in the G1-S phase transition. Inhibitors of CDK4/6 are presently the subjects of numerous studies, and PD 0332991, an inhibitor of CDK4/6, has been used to treat hormone receptor (HR)-positive, advanced-stage breast cancer. This inhibitor has also been studied in other cancers, such as lung cancer. In this review, we will discuss the regulation of the normal cell cycle transition from $\mathrm{G} 1$ to $\mathrm{S}$ phase, the most promising inhibitor of CDK4/6, PD 0332991, as applied in different cancers, and finally we propose a mechanism of acquired resistance as well as the incredible potential for CDK4/6 inhibitors in the treatment of cancer. Briefly, we assert that, going forward, a new treatment pattern for cancer may be a combination therapy with a cell cycle inhibitor and a molecular targeted drug.
\end{abstract}

\section{Contents}

1. Introduction

2. CDKs and cell cycle regulation

3. The Rb-E2F pathway and tumorigenesis

4. Palbociclib and its applications in different cancers

Correspondence to: Professor Jun Chen, Department of Lung Cancer Surgery, Tianjin Medical University General Hospital, 154 Anshan Road, Heping, Tianjin 300052, P.R. China

E-mail: huntercj2004@yahoo.com

Professor Hongyu Liu, Tianjin Key Laboratory of Lung Cancer Metastasis and Tumor Microenvironment, Tianjin Lung Cancer Institute, Tianjin Medical University General Hospital, 154 Anshan Road, Heping, Tianjin 300052, P.R. China

E-mail: liuhongyu123@hotmail.com

Key words: CDK4/6, PD 0332991, breast cancer, lung cancer, drug resistance
5. Applications of palbociclib in different cancers

6. Breast cancer

7. Multiple myeloma

8. Lung cancer

9. Future directions

\section{Introduction}

Activating cyclin-dependent kinases (CDKs) promotes cell cycle progression, and abnormal cell cycle regulation lies at the heart of tumorigenesis (1), leading to uncontrolled cell cycle progression and cell proliferation. Activated CDKs lead to genomic instability (GIN), dysregulated proliferation, and chromosomal instability (CIN), resulting in proliferative advantages and susceptibility to genetic alterations (1). During cell cycle progression, the restriction point from G1-S phase is regulated by CDK4/6 and plays a crucial role in tumorigenesis; thus, inhibitors targeting this transition show promise as clinical therapy (2). Recently, therapeutic regimens targeting a dysregulated cell cycle caused by misregulated CDKs have shown promise in the treatment of diverse cancers. While the first generation of CDK4/6 inhibitors was quickly abandoned because pan-CDK inhibition was toxic to normal cells and led to unacceptable side effects (3), new CDK4/6 inhibitors, such as palbociclib, abemaciclib, and ribociclib (Fig. 1), overcame the disadvantages of the first generation of CDK4/6 inhibitors, showing promising anticancer effects and manageable toxicity. Of these three drugs, palbociclib and ribociclib have recently been approved by the Food and Drug Administration (FDA) as a new treatment strategy in combination with letrozole for hormone receptor (HR)-positive, advanced-stage breast cancer, showing promising results for these patients (4). Additionally, palbociclib has been successfully applied in multiple myeloma therapy. However, further research is required to define the patients who would receive the greatest benefit, test possible combination treatments in other cancers, and interrogate acquired resistance. Finally, to make efforts to establish new treatment pattern, cell cycle inhibitor+molecular targeted drug. In this review, we discuss normal cell cycle regulation associated with CDK4/6 inhibitors as well as the use of palbociclib to treat different cancers and its advantages in clinical application, and propose a new cancer treatment pattern. 


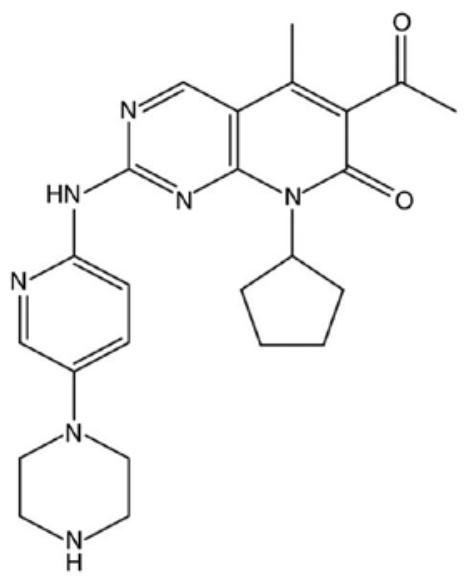

Palbociclib (PD0332991)

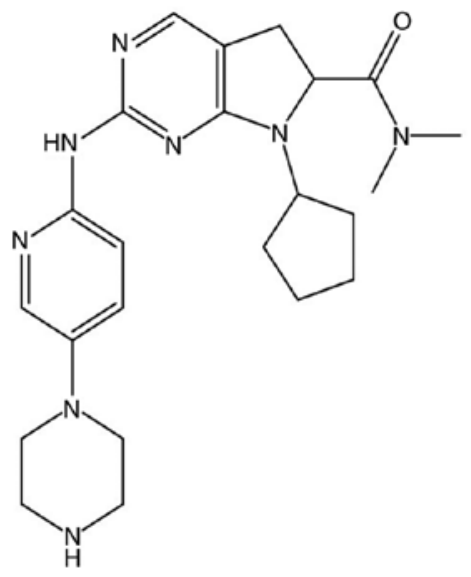

Ribociclib

(LEE011)

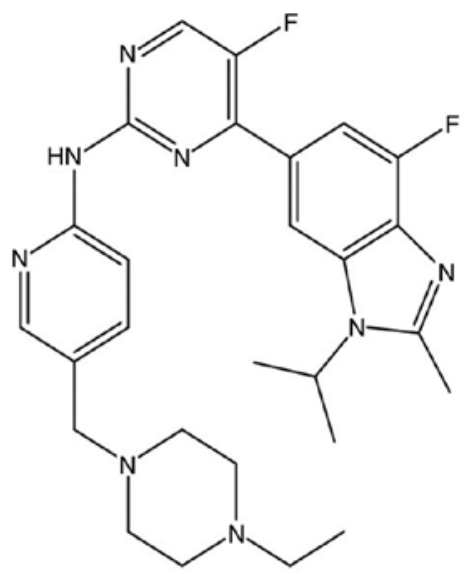

Abemaciclib (LY2835219)

Figure 1. The chemical structures of selective cyclin-dependent kinase (CDK) 4 and 6 inhibitors PD 0332991.

\section{CDKs and cell cycle regulation}

Cell cycle regulation is complex and comprises two major phases: interphase and mitosis (M phase; Fig. 2). The former can be subdivided into three phases: G1 phase for preparing for DNA synthesis, $S$ phase for DNA synthesis, and finally $\mathrm{G} 2$ phase for preparing for cell division. The $\mathrm{M}$ phase includes prophase, metaphase, anaphase, and telophase. After M phase, one cell will have divided into two daughter cells. During interphase, the G1-S transition is a critical restriction point, resulting in one of three fates for the cell: continue cycling, exit active proliferation, or enter a quiescent (G0) state. Many growth factors and inhibitors interact to coordinate cell cycle progression, and the CDK4/6- $\mathrm{Rb}$ pathway $(5,6)$ plays a central role in regulating the $\mathrm{G} 1$ to $\mathrm{S}$ phase transition.

So far, 21 cyclin-dependent kinases (CDKs) have been identified in mammalian cells by the HUGO Gene Nomenclature Committee (HGNC) and the Mouse Genomic Nomenclature Committee (7). These CDKs can be categorized into cell cycle related subfamilies and transcriptional subfamilies on a functional basis (8). The former group includes CDK1 (9), CDK4 (10), CDK6 and CDK5 (11). The latter group includes CDK7 (12), CDK8 (13), CDK9 (14), CDK11 (15-18) and CDK20 (19). This transcriptional group can phosphorylate the c-terminal domain (CTD) of RNAPII. CDKs can also regulate cell cycle progression at different levels (12). For example, CDK7 is a member of the CDK Activating Kinase (CAK, CDK7/CycH/MAT1) complex and is involved in phosphorylating many CDKs (12).

Among the $21 \mathrm{CDKs}$, some are critical to drive cells through G1 phase into $\mathrm{S}$ phase, such as CDK2, CDK4 and CDK6. CDK2, consisting of 298 amino acids, is an important CDK that is involved in the transition from G1 to $\mathrm{S}$ phase and $\mathrm{S}$ phase progression (20). Abnormal CDK2 activation leads to cell cycle disorders and may induce tumorigenesis. It has two associated cyclins that can regulate the cell cycle: cyclins A and E (21). The cyclin A-CDK2 complex is active during $\mathrm{S}$ phase and the cyclin E-CDK2 complex is involved in the G1/S transition by phosphorylating the Rb protein $(22,23)$. Thus, CDK2 inhibition can disrupt the proliferation of cancer

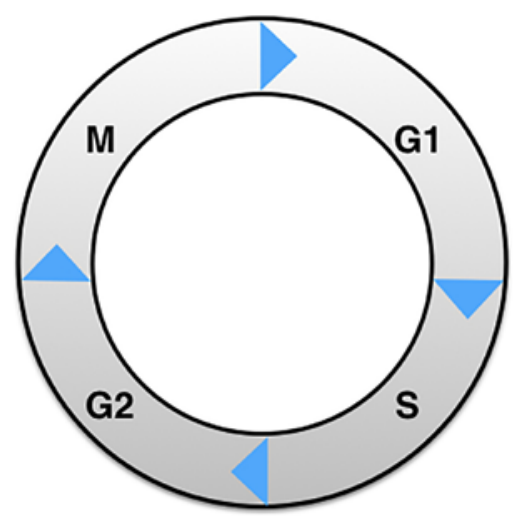

Figure 2. The possible mechanisms of EGFR-TKIs and its acquired resistance.

cells like prostate cancer (24), breast cancer (25) and non-small cell lung cancer (26).

Two important cell cycle regulating CDKs are CDK4 and CDK6, which have pivotal roles in the transition from G1 to S phase. CDK4 and CDK6 are similar in the ircrystal structures and functions (27). External growth factors regulate CDK4 and CDK6, facilitating their combination with cyclin D (D1, D2, D3) to form CDK4/6-cyclin D complexes. These complexes regulate progression through the checkpoint from G1 to S phase in mammalian cells (10). Recent studies have shown that CDK4 and CDK6 can interact outside of the context of cell cycle regulation, leading to tumorigenesis. For example, CDK4 and CDK6 affect vascular endothelial growth factor (VEGF)-B and VEGF-A, respectively. They both have also been identified as regulatorsof inflammatory cytokines through activation of the nuclear factor (NF)- $\mathrm{KB}$ pathway (28). CDK4 and CDK6 are also associated with DNA repair (29), senescence (30) and metabolism (31). In these non-cell cycle functions, the kinase functions of CDK4 and CDK6 play important roles; thus, selective molecules such as palbociclib (PD 0332991), ribociclib (LEE011), and abemaciclib (LY2835219) can disrupt CDK-associated pathways (Fig. 1).

Other functions of CDK family members are shown in Table I. These CDKs all contribute to the progression of tumori- 


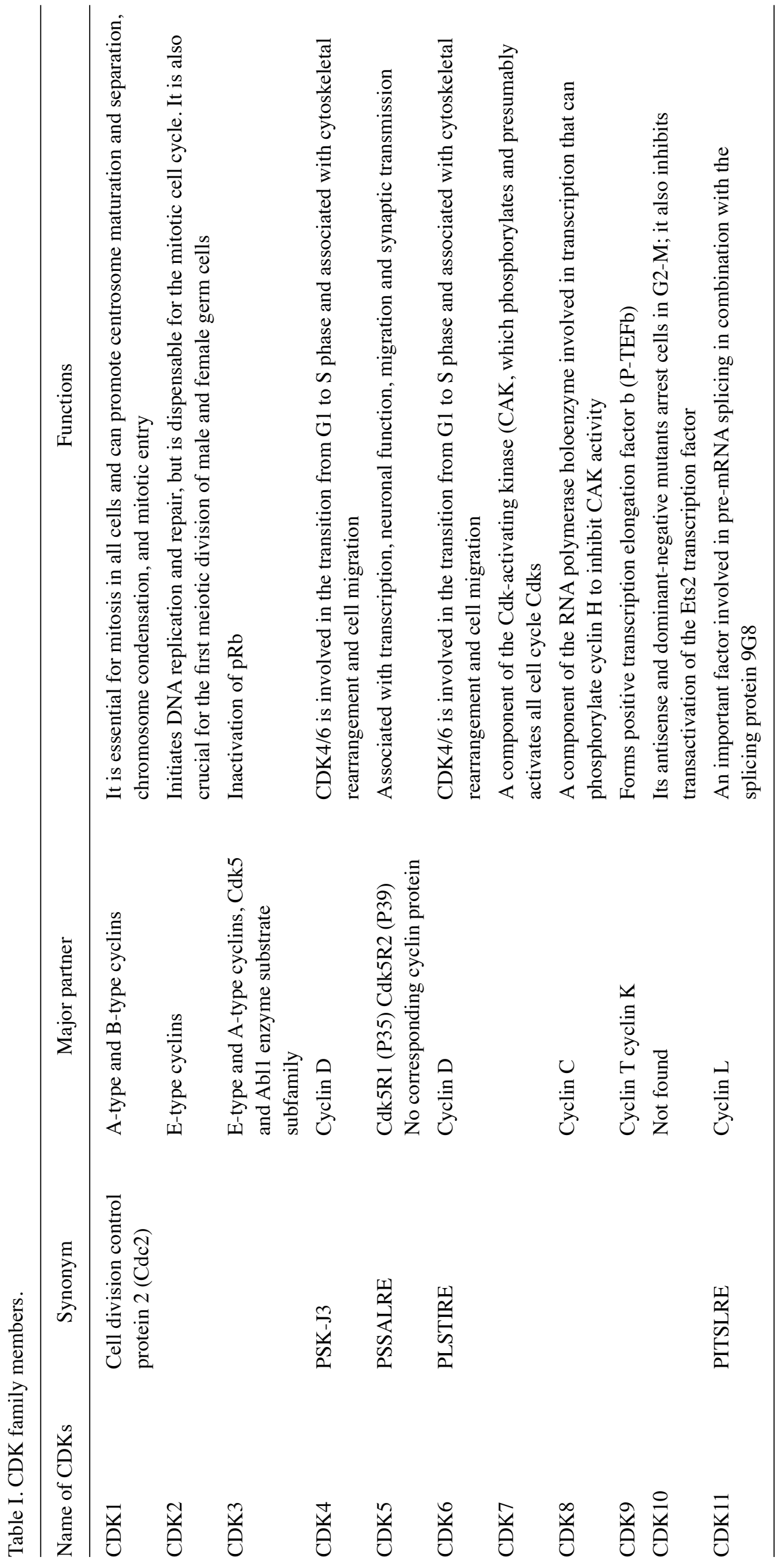


genesis, and some are critical cell cycle modulators. Thus, they may be promising targets for novel cancer treatments.

\section{The Rb-E2F pathway and tumorigenesis}

The retinoblastoma tumor suppressor gene $(\mathrm{Rb})$ was first discovered in human retinoblastoma (1). It is an ancestral protein that regulates cell cycle progression by promoting G1 to $\mathrm{S}$ phase entry. Multiple studies have shown that $\mathrm{Rb}$ functions in diverse cellular pathways, including apoptosis and the cell cycle. Inactivation of the $\mathrm{Rb}$ protein is an event that can occur in most cancers. The mechanisms underlying this inactivation include mutation of $\mathrm{Rb}$ itself, $\mathrm{Rb}$ loss by methylation or chromosomal deletion, or via upstream signaling molecule interactions such as INK4 and K-Ras (32).

Previous studies have identified three Rb family members: $\mathrm{Rb}, \mathrm{p} 107$, and p130. Not all organisms have all three members: most lower and unicellular organisms have only one Rb-related protein that functions in cell cycle progression (33). However, in mammalian cells, $\mathrm{Rb}$ as well as the Rb-like proteins p130 and p107 can all be detected and regulate the cell cycle with BMYB (MYBL2) and Forkhead box M1(FOXM1) (34). In the past few years, many experts have asserted that $\mathrm{Rb}$ is stronger than p107 or p130 with respect to a tumor suppressive function in the cell cycle. Rb gene knockout in mice results in embryonic lethality, which is not seen in p107 or p130 deficient mice $(35,36)$. The precise mechanisms underlying differences in $\mathrm{Rb}, \mathrm{p} 107$ and p130 functions, however, remain unclear.

The other member of the Rb-E2F pathway is E2Fs, a family of transcription factors that regulate cell cycle progression, cellular proliferation, and DNA synthesis (32). E2F is a large family, members of which have many conserved DNA binding domains that bind target promoters and could promote or restrain target gene expression $(37,38)$. The E2F family includes ten members, most of which function as cell cycle regulators. The first group includes the strong transcriptional activators E2F1-E2F3a, which are regulated by Rb. The second group comprises the passive repressors E2F3b-E2F5, which interact with the other Rb family members, p107 and p130, to modulate transcriptional activity of target gene promoters. The third group, E2F6, 7a, 7b and 8, have been identified as active repressors of transcription $(39,40)$. The first group of E2Fs is responsible for promoting proliferation by inhibiting the expression of growth inhibitory proteins like p16, p21 and p27 as well as promoting genes associated with proliferation-related expression in the G1-S transition (41-43). Unlike E2F1-3, E2F4 and E2F5 can be detected uniformly in quiescent (G0) cells, and they function as repressors of E2F-responsive genes (44-46). E2F7 and E2F8 are both important during embryonic development and regulating the E2F1-p53 apoptotic axis as repressors (47). They are highly expressed in mid- to late $\mathrm{S}$ phase, and repress target gene transcription in G1/S (48).

The $\mathrm{Rb}$-E2F pathway is almost always disrupted in human cancers. It is believed that this is the initial hit of most cancers, including lung cancer. The Rb-E2F pathway can regulate tumor progression, influencing angiogenesis and metastasis. Usually, $\mathrm{Rb}$ is inactivated through mutation or deletion and E2F transcription factors are activated, thus leading to increased proliferation in almost all tumors.
In early G1 phase, endogenous or exogenous mitogenic stimuli function induce expression of cyclin D (D1, D2 and D3), and activated cyclin D form complexes with CDK4 and CDK6, termed the cyclin D-CDK4/6 complex. The active complex will then phosphorylate the C-terminal region of $\mathrm{Rb}$ or other members of the $\mathrm{Rb}$ family, depending on cell type $(49,50)$. Hyper-phosphorylated Rb proteins release E2Fs, allowing them to participate in synthesizing $S$ phase initiating proteins. While in the late G1 phase, the previous activation in the early G1 will also participate in the generation of molecules like cyclin $\mathrm{E}$ that will bind and activate CDK2 in the G1/S transition $(51,52)$. The CDK2-cyclin E complex and activated CDK2 can potently phosphorylate and inactivate $\mathrm{Rb}$, simultaneously regulating the protein switch controlled by E2Fs to participate in the transition from G1 to S and DNA replication.

Clearly understanding the mechanism of cell cycle regulation can inform tumor treatment strategies. In the past few years, many targeted therapies for cancer, such as Herceptin and Tarceva, have emerged and changed clinical treatments; however, patient responses are imperfect. Growth signaling pathways are web-like, and blocking all possible cross-talking pathways and feedback loops using one or two drugs is difficult or impossible. The cell cycle, however, is not like a growth pathway: it is a one-way street (53). Thus, inhibitors of cell cycle proteins may be promising in a therapeutic setting.

CDK2 inhibitors are promising and they can be divided into two types according to their binding sites: ATP-competitive and non-ATP-competitive inhibitors. ATP-competitive inhibitors of CDK2 have evolved into second-generation inhibitors, although first generation inhibitors have low inhibitory effects and potent side effects. Second-generation inhibitors of CDK2 have strong anti-proliferative effects, and some are being evaluated in ongoing preclinical and clinical trials, including AT7519 (54), NU2058 (55) and P276-00 (56). The other type of CDK2 inhibitor, non-ATP competitive inhibitors Spa310 (58) and CIP (59), have high specificity and show promise in clinical applications in the treatment of cancer. The mechanisms of these inhibitors center around CDK2-cyclin complexes and binding sites.

The CDK4/6 inhibitors palbociclib (PD0332991), abemaciclib (LY2835219), and ribociclib (LEE011) have also been studied in many types of cancers including breast cancer, multiple myeloma, and lung cancer. Of these CDK inhibitors, palbociclib in particular has been used in phase III clinical trial development (60).

\section{Palbociclib and its applications in different cancers}

Palbociclib (PD0332991, Ibrance $^{\circledR}$, Pfizer Inc.) is an oral, reversible small molecule inhibitor of cyclin-dependent kinases 4 and 6 (CDK4/6). While CDK4/6 can bind cyclin D1, resulting in $\mathrm{Rb}$ hyperphosphorylation, palbociclib can separate CDK4/6-cyclin D1 complexes, blocking Rb phosphorylation and preventing E2F1 release, thus leading to G1 phase arrest and tumor growth suppression (61). The elimination half-life of palbociclib is over $29 \mathrm{~h}$. The primary metabolic region is the liver, being metabolized by SULT2A1 and CYP3A, and the primary excretion routes are feces $(74.1 \%)$ and kidneys $(17.5 \%)$. 


\section{Applications of palbociclib in different cancers}

Since the 1990s, most cell cycle inhibitors produced by Roche, Bristol-Myers Squibb, Kyowa Hakko Kirin, and others have been used in clinical trials. However, these pioneering pan-CDK inhibitors were halted soon thereafter due to a narrow therapeutic window, lack of efficacy in solid tumors, toxicity issues, and challenges with dosing schedules. After years of development, the current CDK4/6 inhibitors became more specific and/or more potent. Specific inhibitors of CDK4/6 appear to be less toxic, have mild bone marrow suppression, are able to be orally administered, and facilitate dosing schedules. These merits have led to their applications in different cancers (62). In 2004, a molecular biologist at Weill Cornell Medical College, Selina Chen-Kiang, demonstrated that palbociclib functions in blood cancer. In almost all cancers, including breast cancer, mutation of $\mathrm{Rb} 1$ or components regulating the CDK-RB-E2F pathway is often observed. Thus, the use of cyclin-dependent kinase (CDK) inhibitors to re-establish cell cycle control has been an attractive therapy in the treatment of breast cancer.

\section{Breast cancer}

Breast cancer is the most commonly-diagnosed tumor in women. More than $75 \%$ of patients diagnosed with metastatic breast cancer are estrogen receptor and progesterone receptor positive (HMR-positive). Compared with other types of metastatic breast cancers, HMR-positive metastatic breast cancer has a more favorable median overall survival (24-36 months) from time of diagnosis (63). When treating this type of breast cancer, the goal is to ensure quality of life, prolonging survival and postponing death. Previously, chemotherapy was thought to be the first-line therapy for HMR-positive breast cancer. In February 2015, however, the Food and Drug Administration (FDA) approved palbociclib as an initial endocrine-based therapy in combination with letrozole in postmenopausal women with HMR-positive, Her2-negative advanced breast cancer (64). Palbociclib is also effective in HR-positive metastatic breast cancer patients with fulvestrant (4).

Until now, the use of the selective CDK4/6 inhibitor palbociclib combined with endocrine therapy to treat estrogen receptor-positive breast cancer patients was the most successful application of CDK inhibition. The data from the PALOMA-I trials showed that letrozole plus palbociclib confers longer median progression-free survival (PFS) than letrozole alone. This study included two phases: phase I and phase II. Slamon et al conducted the phase I portion of PALOMA-I. They assessed the safety and tolerability of palbociclib in combination with letrozole; the most common side effects are leucopenia, neutropenia, and fatigue. The two combined drugs have no pharmacokinetic interaction. Twelve patients were enrolled in this portion, nine of whom had stable disease for $\geq 6$ months, and three of whom had a partial response. Finn et al conducted the phase II portion including two cohorts. The members enrolled in cohort 1 comprise an unselected population to identify the safety and efficacy of the combination of palbociclib and letrozole. In cohort 2, patients with cyclin D1 amplification and/or loss of p16 were enrolled with the goal of identifying the endpoint of investigator-assessed PFS. The median PFS was 20.2 months for the combination as compared to 10.2 months for letrozole alone [hazard ratio $(\mathrm{HR})=0.488$; 95\% confidence interval (CI), 0.319-0.748; 1-sided $\mathrm{P}=0.0004]$. Both PALOMA-I phase studies showed that palbociclib combined with letrozole confers more benefits to breast cancer patients than letrozole alone, and that biomarker-selected patients do not show improved OS.

In recent years, the results of PALOMA-2 showed that in 666 postmenopausal patients with untreated, HR-positive, HER2-negative, metastasis breast cancer treated with palbociclib plus letrozole had longer PFS (24.8 months) and ORR (42.1\%) than letrozole with placebo (14.5 months and $34.7 \%$ respectively). The primary side effects observed in this randomized, double-blind phase 3 trial are myelotoxic effects; other side effects are identical to those observed in PALOMA-1 (65). Biochemical analysis of this trial showed that in the ER-positive, Rb-negative and p16-negative subgroup, PFS is also longer in patients treated with palbociclib and letrozole than with palbociclib and placebo. Thus, the combination of palbciclib and letrozole shows significant results in clinical trials.

PALOMA-3 (66), another important trial, was performed to assess palbociclib in combination with fulvestrant in asecond-line setting. Five hundred and twenty-one patients were enrolled in this clinical trial; among them, two-thirds received $125 \mathrm{mg}$ palbociclib for 3 weeks on and 1 week off, and one-third received a placebo. All patients in this study were also administered $500 \mathrm{mg}$ fulvestrant on days 1, 14, and 28 , then every 28 days thereafter. After 195 PFS events, the results of this double-blind trial were analyzed. Median PFS of the palbociclib-fulvestrant and placebo-fulvestrant groups were 9.2 and 3.8 months, respectively (HR= $0.42 ; 95 \%$ CI, 0.32-0.56; $\mathrm{P}<0.001)$. The five most commonly-experienced side effects in this trial were neutropenia, leukopenia, anemia, thrombocytopenia and fatigue. Aside from these adverse effects, febrile neutropenia was observed in both arms at an incidence of $0.6 \%$. PE was only seen in the palbociclib-fulvestrant groups at an incidence of $0.9 \%$ (67).

Some investigators have also tested CDK4/6 inhibitor monotherapy. A phase I study on palbociclib monotherapy indicated that this drug has promising clinical efficacy and a well-tolerated toxicity profile in patients with $\mathrm{Rb}$-positive advanced solid tumors and non-Hodgkin lymphoma (68). In this study, 33 patients were enrolled and treated with palbociclib (once daily for 14 days on and 7 days off). Among them, nine patients presented with stable disease and one exhibited a partial response. Another CDK4/6 inhibitor, LEE011, was also investigated in a phase I study in patients with advanced solid tumors. LEE011 was well tolerated and almost $40 \%$ of tested patients presented with stable disease; two exhibited a partial response. Similarly, a single-agent study of abemaciclib showed delayed disease progression and activity in metastatic $\mathrm{ER}^{+}$breast cancer. While neutropenia is the principal dose-limiting toxicity of palbociclib and LEE011, it is also a common side effect of cytotoxic agents. As opposed to the neutropenia caused by cytotoxicity, palbociclib and LEE011-induced neutropenia is rapidly reversible (52). While the principle side effect of abemaciclib is gastrointestinal-associated toxicity, neutropenia is also seen, to a lesser extent. The mechanisms of these differences in toxicity are not clear, and require further research. 
$\mathrm{ER}^{+}$breast cancer patients should be treated with endocrine therapy such as aromatase inhibitors (AIs), fulvestrant, ortamoxifen as a first line treatment. If a patient treated with an endocrine agent then progresses, other types of endocrine agents may confer benefits (53). However, nearly all patients will experience an initial effect and eventually develop drug resistance. Although the mechanism of acquired resistance to endocrine therapy has been described in many reports, recent studies have found mutations in the ER gene (ESR1) $(69,70)$, which occur most frequently in post-aromatase inhibitor (AI)-treated breast cancer patients, termed acquired resistance, but rarely occurs in primary breast cancer, which may be an important point. It is hypothesized that the combination of palbociclib and letrozole may reverse acquired resistance in breast cancer patients.

\section{Multiple myeloma}

Multiple myeloma (MM), the second most common hematopoietic cancer, represents another successful application of CDK4/6 inhibition. MM is a malignancy characterized by the uncontrolled proliferation of clonal plasma cells with an incidence of about 20,000 per year in the United States (71). The standard treatment of alkylating agents combined with steroids has been used for over 30 years (72). Other treatments include stem cell transplantation with immunomodulatory therapies and proteasome inhibitors. Although the appearance of new therapies has reversed the poor outcomes associated with relapsed/refractory multiple myeloma (RRMM) (73), overall survival is far from optimal.

In MM, as in other cancers, dysregulation of the cell cycle contributes to disease progression, and CDK4/6 disorders are often seen in MM. Thus, palbociclib has been successfully applied in recent years. A multicenter, open-label, phase I/II study of palbociclib with bortezomib and dexamethasone in RRMM has been completed (74). This study included two phases: phase 1 and phase 2 . The phase 1 study enrolled $\mathrm{Rb}$ protein-positive patients with relapsed and/or refractory $\mathrm{MM}$ after $\geq 1$ previous treatments and a life expectancy $>3$ months to determine the maximum tolerated dose (MTD) and recommended dose of palbociclib to be used in phase 2 . Two schedules were evaluated. For schedule A, palbociclib was given orally once daily for days 1-21 of each 28-day cycle, with 7 days off. For schedule B, palbociclib was given orally once daily for 12 days of a 21-day cycle, with 9 days off. For both schedules A and B, bortezomib was administered intravenously on days $8,11,15$, and 18 in each tested cycle. Aproximately $30 \mathrm{~min}$ before the administration of bortezomib, $20 \mathrm{mg}$ dexamethasone was given orally. Of the 21 patients who were enrolled in phase 1, nine were grouped in Schedule A (three patients were administered $100 \mathrm{mg}$ palbociclib and the remaining patients were administered $75 \mathrm{mg}$ at the onset), and 12 patients grouped in Schedule B (seven patients were administered $100 \mathrm{mg}$ palbociclib and the remaining patients were administered $125 \mathrm{mg}$ at the onset). Observed side effects are shown in Table II.

For Schedule A, the objective response rate (ORR) was $16.7 \%$. One patient who received $100 \mathrm{mg}$ palbociclib had progressive disease. Of the patients who received $75 \mathrm{mg}$ palbociclib, one had a very good partial response $(20 \%$; duration, 6.1 months), one had stable disease (20\%; duration, 1 month), and the last three had progressive disease $(60 \%)$. For Schedule B, the ORR was $8 \%$. In the $100 \mathrm{mg}$ palbociclib group, four patients had stable disease [57\%; median (range) duration, 3.2 (2.3-5.6) months] and three had progressive disease (43\%). In the $125 \mathrm{mg}$ palbociclib group, one patient had a very good partial response (20\%; duration, 2.1 months), two had stable disease (40\%; duration, 6.0 and 10.9 months), one had progressive disease (20\%), and one had an indeterminate response (20\%). According to phase 1 analyses (Schedule A and B), the dose schedule applied in phase 2 was $100 \mathrm{mg}$ palbociclibin combination with $1.0 \mathrm{mg} / \mathrm{m}^{2}$ bortezomib and $20 \mathrm{mg}$ dexamethasone.

Phase 2 of the study included two stages. Forty-two patients were enrolled in phase 2 , with 25 enrolled in stage 1 and 17 in stage 2 . The primary endpoint was antitumor activity based on overall response rate (ORR). Safety, duration of response in objective response patients, progression-free survival (PFS), time to tumor progression, and overall survival (OS) were secondary endpoints. Upon completion of phase 2, 32 patients remained and 30 received $\geq 1$ dose of study treatment; only one patient completed the entire study treatment. Reasons for discontinuation in the 31 patients who did not complete treatment included disease progression $(n=16 ; 53 \%), A E(n=4 ; 13 \%)$, global health status deterioration $(n=2 ; 7 \%)$; withdrawal of consent $(n=2 ; 7 \%)$, and other $[n=5 ; 17 \%$ : moderate response $(n=2 ; 7 \%)$; lack of clinical benefit $(n=1)$; and lack of efficacy $(n=1)]$. Five $(20 \%)$ of the 25 evaluable patients reached the objective response. The objective response median (range) time was 2.8 (0.7-3.5) months within four cycles. Eleven of 25 patients had stable disease lasting a median of 3.9 months. Another seven patients had responses that preceded to stage 2. Twenty-six percent of the patients maintained PFS at 12 months, 17 patients had objective progression, 13 were censored, and six ceased treatment before progression.

Phase 1 of this study identified that the treatment plan of $100 \mathrm{mg}$ palbociclib $+1.0 \mathrm{mg} / \mathrm{m}^{2}$ bortezomib $+20 \mathrm{mg}$ dexamethasone is safe for patients. The most common side effect seen in this study was thrombocytopenia, and the total burden of side effects of this treatment regimen was light. In phase 2 of the study, the ORR was much higher in patients who had not received bortezomib treatment than in those who had received prior treatment with bortezomib (75).

The response topalbociclibin clinical settings in recent years has been modest. This inhibitor can not target other critical myeloma oncogenic kinases. Recently, Perumal et al discovered that a new dual inhibitor of CDK4 and ARK5, ON123300, can rapidly induce cell cycle arrest and apoptosis in vitro and can effectively shrink xenografted tumors in vivo (76). AMPK-related protein kinase 5 (ARK5), which is expressed in nearly all myeloma cell lines, is a member of the AMPK family that is involved in tumor growth and invasion (77). Thus, these results provide promising evidence for ARK5 inhibition and lay a solid foundation for developing the next generation of CDK inhibitors.

\section{Lung cancer}

The application of CDK4/6 inhibitors in lung cancer has also increased in recent years. Although the emergence of 
Table II. Treatment-related adverse events in phase $1^{\mathrm{a}}$ and phase $2^{\mathrm{b}}$.

A,

\begin{tabular}{|c|c|c|c|c|c|c|c|c|c|}
\hline \multirow[b]{2}{*}{ Phase 1 event, n (\%) } & \multicolumn{3}{|c|}{ Schedule A $(n=9)$} & \multicolumn{3}{|c|}{ Schedule B $(n=12)$} & \multicolumn{3}{|c|}{ Total $(\mathrm{N}=21)$} \\
\hline & Grade $1 / 2$ & Grade 3 & Grade 4 & Grade $1 / 2$ & Grade 3 & Grade $4^{c}$ & Grade $1 / 2$ & Grade 3 & Grade 4 \\
\hline Thrombocytopenia & 0 & $1(11)$ & $7(78)$ & 0 & $3(25)$ & $5(42)$ & 0 & $4(19)$ & $12(57)$ \\
\hline Neutropenia & $2(22)$ & $4(44)$ & $1(11)$ & $1(8)$ & $2(17)$ & $3(5)$ & $3(14)$ & $6(29)$ & $4(19)$ \\
\hline Lymphopenia & 0 & 0 & 0 & $4(33)$ & 0 & $1(8)$ & $4(19)$ & 0 & $1(15)$ \\
\hline Neutrophils decreased & 0 & 0 & 0 & $4(33)$ & $1(8)$ & 0 & $4(19)$ & $1(5)$ & 0 \\
\hline Hemoglobin decreased & 0 & 0 & 0 & $1(8)$ & $2(17)$ & 0 & $1(5)$ & $2(10)$ & 0 \\
\hline Leukopenia & 0 & 0 & 0 & $2(17)$ & $1(8)$ & 0 & $2(10)$ & $1(5)$ & 0 \\
\hline $\begin{array}{l}\text { White blood cells } \\
\text { decreased }\end{array}$ & 0 & 0 & 0 & $2(17)$ & $1(8)$ & 0 & $2(10)$ & $1 \quad(5)$ & 0 \\
\hline Anemia & $1(11)$ & $1(11)$ & 0 & 0 & $2(17)$ & 0 & 1 & 3 (14) & 0 \\
\hline Rash & 0 & 0 & 0 & $2(17)$ & 0 & 0 & $2(10)$ & 0 & 0 \\
\hline
\end{tabular}

B,

\begin{tabular}{|c|c|c|c|c|c|c|}
\hline \multirow[b]{2}{*}{ Phase 2 event, n (\%) } & & & & \multicolumn{3}{|c|}{ Schedule B $(n=30)$} \\
\hline & \multicolumn{3}{|c|}{ Schedule A (not assessed) } & Grade $1 / 2$ & Grade $3^{\mathrm{d}}$ & Grade 4 \\
\hline Thrombocytopenia & - & - & - & $3(10)$ & $4(13)$ & $8(27)$ \\
\hline Anemia & - & - & - & $4(13)$ & $8(27)$ & 0 \\
\hline Fatigue & - & - & - & $10(33)$ & $2(7)$ & 0 \\
\hline Nausea & - & - & - & $9(30)$ & 0 & 0 \\
\hline Diarrhea & - & - & - & $6(20)$ & 0 & 0 \\
\hline Neutropenia & - & - & - & $1 \quad(3)$ & $3(10)$ & $2(7)$ \\
\hline Dyspnea & - & - & - & $4(13)$ & 0 & 0 \\
\hline Headache & - & - & - & $3(10)$ & 0 & 0 \\
\hline Peripheral edema & - & - & - & $3(10)$ & 0 & 0 \\
\hline Nasopharyngitis & - & - & - & $3(10)$ & 0 & 0 \\
\hline Peripheral neuropathy & - & - & - & $4(13)$ & 0 & 0 \\
\hline Leukopenia & - & - & - & 0 & $2(7)$ & $2(7)$ \\
\hline Dizziness & - & - & - & $4(13)$ & 1 (3) & 0 \\
\hline Pyrexia & - & - & - & $6(20)$ & 0 & 0 \\
\hline
\end{tabular}

${ }^{a}$ Events considered to be related to palbociclib alone or palbciclib and bortezomb and/or dexamethasone occurring in $>1$ patient in either schedule. ${ }^{b}$ Events considered related to palbociclib alone or palbociclib and bortezomib and/or dexamethasone occurring in $\geq 10 \%$ of patients. ${ }^{\mathrm{c}}$ One patient experienced grade 4 febrile neutropenia. ${ }^{\mathrm{d}}$ Two patients experienced grade 3 febrile neutropenia.

targeted therapies in lung adenocarcinoma (LUAD) have led to positive initial effects for patients with EGFR mutation or EML4-ALK rearrangements, recent data have shown that patients with LUAD have longer PFS when they are treated with targeted therapy as compared to traditional chemotherapy (78). Unfortunately, despite the success of targeted therapy in LUAD patients, almost all cases eventually recur after a median of approximately 10 months from the onset of treatment. This phenomenon may be the greatest challenge for the application of targeted therapy in lung cancer.

Our group has found that the combination of EGFR tyrosine kinase inhibitors (EGFR-TKIs) and palbociclib can reduce proliferation and induce cell apoptosis and G0/G1 cell cycle arrest in EGFR-TKI sensitive and resistant cell lines to a greater extent than gefitinib alone. In vivo experiments, we found that mice treated with palbociclib and gefitinib had more rapid tumor regression and a delayed relapse pattern as compared to mice treated with gefitinib alone. Tumors from the experimental mice showed significantly reduced proliferation, increased apoptosis, and reduced angiogenesis (79).

In our department, many LUAD patients are treated with EGFR-TKIs and eventually develop drug resistance. Three of these patients are receiving palbociclib in an attempt to treat their resistant disease, with fully informed consent. Two of these patients developed stable disease and one had a partial response to palbociclib. We previously reported a 63-year-old 
Table III. Cell cycle inhibitors.

Name

Mechanism of cell cycle inhibitor

BIX-01294

OAMDP

MEK162

Tinospora cordifolia

Yangyinjiedu (YYJD)

Prim-O-glucosylcimifugin

Glucosamine
Could upregulate P21 and induces cell cycle arrest in the phase G0/G1 in acute T lymphoblastic leukemia cells

Induces $\mathrm{S}$ or $\mathrm{G} 2 / \mathrm{M}$ phase arrest by modulating cycle regulatory proteins in hepatoma $\mathrm{HepG} 2$ cells Downregulates and dephosphorylates the cell cycle checkpoint proteins CDK1/CDK2/WEE1 in glioblastoma

Arrests the cell cycle in G0/G1-phase in human oral squamous cell carcinoma cells Induces $\mathrm{G} 2 / \mathrm{M}$ phase arrest in lung cancer cells

Arrests acute lymphoblastic leukemia cells in G2/M phase by downregulating phosphorylated CDK1 levels

Arrests renal cell carcinoma cells in G0/G1 phase by downregulating cyclin D1, CDK4 and CDK6 and upregulating $\mathrm{p} 21$ and $\mathrm{p} 53$ woman with bone and lung metastases who had received gefitinib (250 mg per os (PO) daily) and zoledronic acid (0.4 mg infusion monthly). After treatment, her metastasis was controlled. However, a brain metastasis was found, indicating that her disease had progressed and that she had developed drug resistance to EGFR-TKI. The patient was then administered palbociclib (100 mg PO) and gefitinib continued. Three weeks later, an MRI examination revealed the brain metastasis had disappeared, and the pain caused by bone metastasis was reduced (79).

In KRAS-mutant non-small cell lung cancer (NSCLC) patients, accounting for almost $20 \%$ of NSCLC patients, KRAS mutation can constitutively activate mitogen-activated protein kinase (MAPK) signaling, leading to increased proliferation. This mutation can also decrease efficacy and resistance to chemotherapies and radiotherapy (80). Blocking KRAS activity with small molecules remains difficult because K-RAS can activate multiple pathways such as MEK/ERK, PI3K/AKT and $\mathrm{NF}-\kappa \mathrm{B}$ (81); thus, targeted therapy in KRAS-mutant NSCLC has not been widely employed. Recently, Lu et al found that the combination of MEK (trametinib, GSK112012) and CDK4/6 inhibition (palbociclib) can strongly reduce cell proliferation in KRAS-mutant NSCLCs that were previous resistant to MEK inhibitor in vitro and in vivo (82). Lu et al elucidated that resistance to MEK inhibition is associated with p16 mutation status. The application of palbociclib in KRAS-mutant NSCLC cells can trigger radio-sensitizing effects, apoptosis, and cell cycle arrest with trametinib.

Aside from research on palbociclib use in lung cancer, other CDK4/6 inhibitors such as abeamciclib (LY2835219) and ribociclib (LEE011) are also in different research stages in squamous cell lung cancer (LUSQ). No effective small molecule inhibitors have been discovered for the treatment of LUSQ. However, a study profiling 178 patients showed that CDK4/6-Rb-E2F pathway alterations are commonly observed in LUSQ (83). Thus, CDK4/6 inhibitor maybe an attractive target point in the treatment of LUSQ. In vitro, both palbociclib and LEE011 can potently inhibit Rb phosphorylation at S780, a canonical substrate of CDK4, in H157 and other cell lines. Compared with LEE011, palbociclib may be more effective. Both CDK4/6 inhibitors can inhibit CDK4/6 and CDK9, and

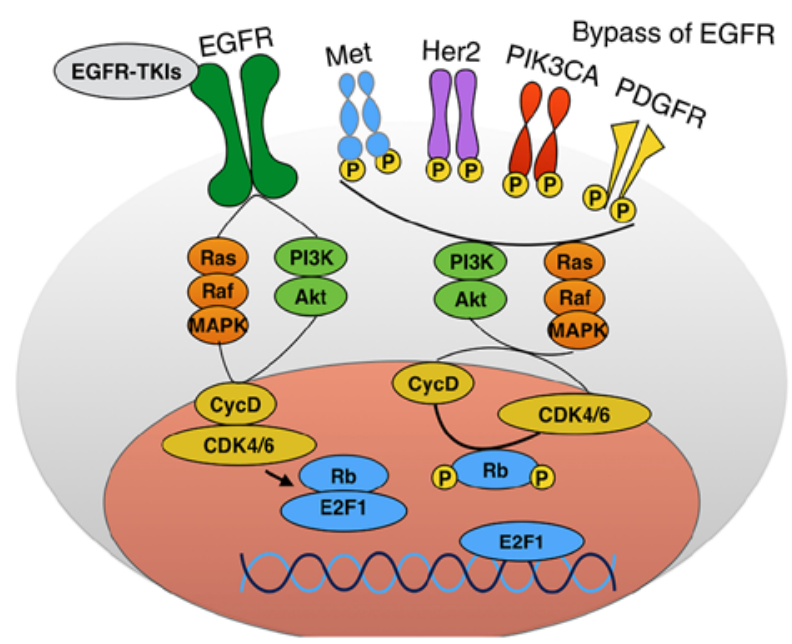

Figure 3. The mechanisms of EGFR-TKIs acquired resistance in lung cancer. The activation of the bypass of EGFR like Met, Her2, PIK3CA and PDGFR is the associated mechanism of EGFR-TKIs acquired resistance in the treatment of lung cancer. The activated bypass of EGFR stimulates the cell cycle pathway, Rb-E2Fs pathway, through PI3K and MAPK pathway. Then the freed E2Fs participate in the lung cancer cell proliferation, and resulting in acquired resistance.

palbociclib can also affect several other kinases, such as case in kinase 2 and PIK3R4, that are associated with autophagy, and several lipid kinases such as PIK3CD and PIP4K2A/B/C. Palbociclib, but not LEE011, was observed to modulate autophagy and AKT pathway inhibition. The application of CDK4/6 inhibitors requires significant research before clinical use, however. Additionally to these three CDK4/6 inhibitors, other cell cycle inhibitors like enterolactone, a rich source of the plant lignan secoisolariciresinol diglucoside, could inhibit the growth of NSCLC cell lines by arresting the cell cycle in G1 phase (84). Many mechanisms underlying the effects of such drugs are not clear and the targeted persons have not been identified, so there is a long way to go.

Some research has shown that the CDK4-Rb-E2F pathway can regulate pancreatic $\beta$-cell size and function, skeletal muscle metabolism, and white adipose cell function. Currently, palbociclib is in clinical trials for the treatment 
of primary brain tumors. According to previous research, primary brain tumors like glioblastoma multiforme (GBM) also have dysregulated CDK4/6 activity. Thus, palbociclib may be a promising clinical drug that can be used in brain tumor treatment. One problem to overcome for clinical palbociclib use may be the blood-brain barrier (BBB), which can limit the delivery of palbociclib to invasive regions of GBM. A team of researchers have found that palbociclib is a substrate for both P-glycoprotein and breast cancer resistance protein, which are both efflux transporters involved in limiting brain distribution of palbociclib. In murine experiments, they have used the transporter-deficient and wild-type models to compare palbociclib delivery to the brain: palbociclib delivery in the transporter-deficient model was 115-fold higher than in the wild-type model. These experimental results have positive implications for the clinical use of palbociclib.

Though the future of CDK4/6 inhibitors is bright, many significant problems remain. Which patients would most benefit from such treatment need to be identified, acquired resistance of CDK4/6 inhibitors must be interrogated, and a clear mechanism of action must be determined. Once these problems have been resolved, its combination with traditional therapy may prove a safe and effective method to apply in cancer.

\section{Future directions}

Presently, the use of targeted therapy is thought to be promising for many kinds of cancers. However, the big hurdle that must be resolved immediately is acquired resistance. We found that acquired resistance is likely caused by mutation in or amplification of the targeted kinase itself or activation of a compensatory kinase (85-88). Both of these alterations can lead to substantial tumor cell proliferation, as shown in Fig. 3. Regarding acquired resistance, we hypothesize that blocking one or two growth pathways is insufficient to inhibit tumor cell proliferation. However, all cells must progress through the cell cycle in order to proliferate; thus, cell cycle inhibitors may be the promising agents that can be used to treat cancer. As shown in Fig. 3, when EGFR or other growth pathways, such as Met, Her2 or PDGFR, are mutated and activated, all downstream pathways will activate cell cycle progression. Thus, we propose that cancer treatment should focus on combining cell cycle inhibitors with small molecule inhibitors.

The FDA has approved the CDK4/6 inhibitor PD 0332991 for combination use in treating postmenopausal ER-positive/HER2-negative advanced breast cancer with letrozole as first-line therapy. Other combination therapies including a cell cycle inhibitor and targeted therapy have been described. In colorectal cancer (CRC) with KRAS mutation, the combination of CDK4/6 and MEK inhibitors are effective in CRC cells and will be studied in planned phase II clinical trials (89). In cutaneous melanoma, PD 0332991 can be combined with MEK inhibitor (89). CDK4/6 inhibitors can be combined with phosphatidylinositol 3-kinase (PI3K) pathway inhibitors for $\mathrm{HR}^{+}$breast cancer, and with $\mathrm{RAF}$ and MEK inhibitors for melanoma with MAPK-activating mutations (2).

In addition to CDK4/6 inhibitors, other CDK and cell cycle inhibitors (Table III) are being actively pursued, such the first covalent inhibitor of CDK7, THZ1. This inhibitor is a promising and effective drug that can suppress cancer progression, and Kwiatkowski et al have asserted that it is an effective anti-proliferative agent in blood cancers and Jurkat cells (90). Thus, in almost every kind of tumor, dysregulation of the cell cycle is often seen and leads to tumor progression. We therefore propose that combination therapy with a cell cycle inhibitor and targeted drug may prove effective in reversing acquired resistance and potentiate the effect of targeted therapy.

Though the future of CDK4/6 inhibition is bright, many questions remain including how to identify optimal patients, understanding mechanisms of acquired resistance to CDK4/6 inhibitors, and overcoming acquired resistance. Nonetheless, we assert that its combination with traditional therapy may be a safe and effective means to treat cancer.

\section{Acknowledgements}

This study was supported by grants from the National Natural Science Foundation of China (to Jun Chen, no. 81773207, to Hongyu Liu, no. 81372306) and the Tianjin key project of the Natural Science Foundation (to Jun Chen, 16JCZDJC34200), Special support program for High Tech Leader \& Team of Tianjin (to Jun Chen), Tianjin Natural Science Foundation (to Hongyu Liu, 13JCYBJC22600, 16PTSYJC00160), and the Ph.D. Programs Foundation from the Ministry of Education of China (to Jun Chen, 20131202110004).

\section{References}

1. Minton K: Cancer immunotherapy: Cell cycle inhibitors boost tumour immunogenicity. Nat Rev Drug Dis 16: 679, 2017.

2. Hamilton $E$ and Infante JR: Targeting CDK4/6 in patients with cancer. Cancer Treat Rev 45: 129-138, 2016.

3. Zhou J, Zhang S, Chen X, Zheng X, Yao Y, Lu G and Zhou J: Palbociclib, a selective CDK4/6 inhibitor, enhances the effect of selumetinib in RAS-driven non-small cell lung cancer. Cancer Lett 408: 130-137, 2017.

4. Bilgin B, Sendur MA, Şener Dede D, Akıncı MB and Yalçın B: A current and comprehensive review of cyclin-dependent kinase inhibitors for the treatment of metastatic breast cancer. Curr Med Res Opin 33: 1559-1569, 2017.

5. Chen L and Pan J: Dual cyclin-dependent kinase 4/6 inhibition by PD-0332991 induces apoptosis and senescence in oesophageal squamous cell carcinoma cells. Br J Pharmacol 174: 2427-2443, 2017.

6. Patel P, Asbach B, Shteyn E, Gomez C, Coltoff A, Bhuyan S, Tyner AL, Wagner R and Blain SW: Brk/Protein tyrosine kinase 6 phosphorylates p27 $7^{\mathrm{KIP} 1}$, regulating the activity of cyclin D-cyclin-dependent kinase 4. Mol Cell Biol 35: 1506-1522, 2015.

7. Malumbres M, Harlow E, Hunt T, Hunter T, Lahti JM, Manning G, Morgan DO, Tsai LH and Wolgemuth DJ: Cyclin-dependent kinases: A family portrait. Nat Cell Biol 11: 1275-1276, 2009.

8. Malumbres M: Cyclin-dependent kinases. Genome Biology 15: $122,2014$.

9. Ubersax JA, Woodbury EL, Quang PN, Paraz M, Blethrow JD, Shah K, Shokat KM and Morgan DO: Targets of the cyclindependent kinase Cdk1. Nature 425: 859-864, 2003.

10. Baker SJ and Reddy EP: CDK4: A key player in the cell cycle, development, and cancer. Genes Cancer 3: 658-669, 2012.

11. Shah K and Lahiri DK: Cdk5 activity in the brain-multiple paths of regulation. J Cell Sci 127: 2391-2400, 2014.

12. Pinhero R and Yankulov K: Expression and purification of recombinant CDKs: CDK7, CDK8, and CDK9. Methods Mol Biol 1336: 13-28, 2016.

13. Galbraith MD, Donner AJ and Espinosa JM: CDK8: A positive regulator of transcription. Transcription 1: 4-12, 2010.

14. Krystof V, Baumli S and Fürst R: Perspective of cyclin-dependent kinase 9 (CDK9) as a drug target. Curr Pharm Des 18: 2883-2890, 2012. 
15. Hu D, Mayeda A, Trembley JH, Lahti JM and Kidd VJ: CDK11 complexes promote pre-mRNA splicing. J Biol Chem 278: 8623-8629, 2003.

16. Chi Y, Huang S, Peng H, Liu M, Zhao J, Shao Z and Wu J: Critical role of CDK11(p58) in human breast cancer growth and angiogenesis. BMC Cancer 15: 701, 2015.

17. Bajić VP, Su B, Lee HG, Kudo W, Siedlak SL, Zivković L, Spremo-Potparević B, Djelic N, Milicevic Z, Singh AK, et al: Mislocalization of CDK11/PITSLRE, a regulator of the $\mathrm{G} 2 / \mathrm{M}$ phase of the cell cycle, in Alzheimer disease. Cell Mol Biol Lett 16: 359-372, 2011.

18. Zhou Y, Han C, Li D, Yu Z, Li F, Li F, An Q, Bai H, Zhang X, Duan Z and Kan Q: Cyclin-dependent kinase 11(p110) (CDK11(p110)) is crucial for human breast cancer cell proliferation and growth. Sci Rep 5: 10433, 2015.

19. Malumbres M and Barbacid M: Mammalian cyclin-dependent kinases. Trends Biochem Sci 30: 630-641, 2005

20. Shapiro GI: Cyclin-dependent kinase pathways as targets for cancer treatment. J Clin Oncol 24: 1770-1783, 2006.

21. Sakurikar N and Eastman A: Critical reanalysis of the methods that discriminate the activity of CDK2 from CDK1. Cell Cycle 15: 1184-1188, 2016.

22. Sherr CJ: G1 phase progression: Cycling on cue. Cell 79: 551-555, 1994.

23. Li Y, Zhang J, Gao W, Zhang L, Pan Y, Zhang S and Wang Y: Insights on structural characteristics and ligand binding mechanisms of CDK2. Int J Mol Sci 16: 9314-9340, 2015

24. Flores O, Wang Z, Knudsen KE and Burnstein KL: Nuclear targeting of cyclin-dependent kinase 2 reveals essential roles of cyclin-dependent kinase 2 localization and cyclin $\mathrm{E}$ in vitamin D-mediated growth inhibition. Endocrinology 151: 896-908, 2010.

25. Ali S, Heathcote DA, Kroll SH, Jogalekar AS, Scheiper B, Pate H, Brackow J, Siwicka A, Fuchter MJ, Periyasamy M, et al: The development of a selective cyclin-dependent kinase inhibitor that shows antitumor activity. Cancer Res 69: 6208-6215, 2009.

26. Kawana H, Tamaru J, Tanaka T, Hirai A, Saito Y, Kitagawa M, Mikata A, Harigaya K and Kuriyama T: Role of p27 Kipl and cyclin-dependent kinase 2 in the proliferation of non-small cell lung cancer. Am J Pathol 153: 505-513, 1998

27. Morgan DO: Cyclin-dependent kinases: Engines, clocks, and microprocessors. Annu Rev Cell Dev Biol 13: 261-291, 1997.

28. Clark AS, Karasic TB, DeMichele A, Vaughn DJ, O'Hara M, Perini R, Zhang P, Lal P, Feldman M, Gallagher M and O'Dwyer PJ: Palbociclib (PD0332991) - a selective and potent cyclin-dependent kinase inhibitor: A review of pharmacodynamics and clinical development. JAMA Oncol 2: 253-260, 2016

29. Dean JL, McClendon AK and Knudsen ES: Modification of the DNA damage response by therapeutic CDK4/6 inhibition. J Biol Chem 287: 29075-29087, 2012.

30. Rader J, Russell MR, Hart LS, Nakazawa MS, Belcastro LT, Martinez D, Li Y, Carpenter EL, Attiyeh EF, Diskin SJ, et al: Dual CDK4/CDK6 inhibition induces cell-cycle arrest and senescence in neuroblastoma. Clin Cancer Res 19: 6173-6182, 2013.

31. Lee Y, Dominy JE, Choi YJ, Jurczak M, Tolliday N, Camporez JP, Chim H, Lim JH, Ruan HB, Yang X, et al: Cyclin D1-Cdk4 controls glucose metabolism independently of cell cycle progression. Nature 510: 547-551, 2014

32. Weijts BGMW, Westendorp B, Hien BT, Martínez-López LM, Zijp M, Thurlings I, Thomas RE, Schulte-Merker S, Bakker WJ and de Bruin A: Atypical E2Fs inhibit tumor angiogenesis. Oncogene: Sep 18, 2017 (Epub ahead of print). doi:10.1038/onc.2017.336

33. Wirt SE and Sage J: p107 in the public eye: An Rb under study and more. Cell Div 5: 9, 2010.

34. Sadasivam S and DeCaprio JA: The DREAM complex: Master coordinator of cell cycle-dependent gene expression. Nat Rev Cancer 13: 585-595, 2013.

35. Lee MH, Williams BO, Mulligan G, Mukai S, Bronson RT, Dyson N, Harlow E and Jacks T: Targeted disruption of p107: Functional overlap between p107 and Rb. Genes Dev 10: $1621-1632,1996$

36. Cobrinik D, Lee MH, Hannon G, Mulligan G, Bronson RT Dyson N, Harlow E, Beach D, Weinberg RA and Jacks T: Shared role of the pRB-related p130 and p107 proteins in limb development. Genes Dev 10: 1633-1644, 1996.

37. Shen Y, Nar R, Fan AX, Aryan M, Hossain MA, Gurumurthy A Wassel PC, Tang M, Lu J, Strouboulis J and Bungert J: Functional interrelationship between TFII-I and E2F transcription factors at specific cell cycle gene loci. J Cell Biochem 119: 712-722, 2018.
38. Kent LN, Bae S, Tsai SY, Tang X, Srivastava A, Koivisto C, Martin CK, Ridolfi E, Miller GC, Zorko SM, et al: Dosagedependent copy number gains in E2f1 and E2f3 drive hepatocellular carcinoma. J Clin Invest 127: 830-842, 2017.

39. Conklin JF and Sage J: Keeping an eye on retinoblastoma control of human embryonic stem cells. J Cell Biochem 108: 1023-1030, 2009.

40. Dyson N: The regulation of E2F by pRB-family proteins. Genes Dev 12: 2245-2262, 1998

41. Lukas J, Petersen BO, Holm K, Bartek J and Helin K: Deregulated expression of E2F family members induces S-phase entry and overcomes p16INK4A-mediated growth suppression. Mol Cell Biol 16: 1047-1057, 1996.

42. Asano M, Nevins JR and Wharton RP: Ectopic E2F expression induces $\mathrm{S}$ phase and apoptosis in Drosophila imaginal discs. Genes Dev 10: 1422-1432, 1996.

43. DeGregori J, Leone G, Ohtani K, Miron A and Nevins JR: E2F-1 accumulation bypasses a G1 arrest resulting from the inhibition of G1 cyclin-dependent kinase activity. Genes Dev 9: 2873-2887, 1995.

44. Allen KE, la Luna de S, Kerkhoven RM, Bernards R and La Thangue NB: Distinct mechanisms of nuclear accumulation regulate the functional consequence of $\mathrm{E} 2 \mathrm{~F}$ transcription factors. J Cell Sci 110: 2819-2831, 1997.

45. Müller H, Moroni MC, Vigo E, Petersen BO, Bartek J and Helin K: Induction of S-phase entry by E2F transcription factors depends on their nuclear localization. Mol Cell Biol 17: 5508-5520, 1997.

46. Wu Z, Zheng S and Yu Q: The E2F family and the role of E2F1 in apoptosis. Int J Biochem Cell Biol 41: 2389-2397, 2009.

47. Li J, Ran C, Li E, Gordon F, Comstock G, Siddiqui H, Cleghorn W, Chen HZ, Kornacker K, Liu CG, et al: Synergistic function of E2F7 and E2F8 is essential for cell survival and embryonic development. Dev Cell 14: 62-75, 2008.

48. Westendorp B, Mokry M, Groot Koerkamp MJ, Holstege FC, Cuppen E and de Bruin A: E2F7 represses a network of oscillating cell cycle genes to control S-phase progression. Nucleic Acids Res 40: 3511-3523, 2012.

49. Lundberg AS and Weinberg RA: Functional inactivation of the retinoblastoma protein requires sequential modification by at least two distinct cyclin-cdk complexes. Mol Cell Biol 18: 753-761, 1998.

50. Ezhevsky SA, Ho A, Becker-Hapak M, Davis PK and Dowdy SF: Differential regulation of retinoblastoma tumor suppressor protein by G(1) cyclin-dependent kinase complexes in vivo. Mol Cell Biol 21: 4773-4784, 2001.

51. Harbour JW, Luo RX, Dei Santi A, Postigo AA and Dean DC: Cdk phosphorylation triggers sequential intramolecular interactions that progressively block $\mathrm{Rb}$ functions as cells move through G1. Cell 98: 859-869, 1999.

52. van den Heuvel S and Harlow E: Distinct roles for cyclin-dependent kinases in cell cycle control. Science 262: 2050-2054, 1993.

53. Garber K: The cancer drug that almost wasn't. Science 345 : 865-867, 2014

54. Dolman ME, Poon E, Ebus ME, den Hartog IJ, van Noesel CJ, Jamin Y, Hallsworth A, Robinson SP, Petrie K, Sparidans RW, et al: Cyclin-dependent kinase inhibitor AT7519 as a potential drug for MYCN-dependent neuroblastoma. Clin Cancer Res 21: 5100-5109, 2015.

55. Rigas AC, Robson CN and Curtin NJ: Therapeutic potential of CDK inhibitor NU2058 in androgen-independent prostate cancer. Oncogene 26: 7611-7619, 2007.

56. Joshi KS, Rathos MJ, Mahajan P, Wagh V, Shenoy S, Bhatia D, Chile S, Sivakumar M, Maier A, Fiebig HH and Sharma S: P276-00, a novel cyclin-dependent inhibitor induces G1-G2 arrest, shows antitumor activity on cisplatin-resistant cells and significant in vivo efficacy in tumor models. Mol Cancer Ther 6 : 926-934, 2007.

57. Joshi KS, Rathos MJ, Joshi RD, Sivakumar M, Mascarenhas M, Kamble S, Lal B and Sharma S: In vitro antitumor properties of a novel cyclin-dependent kinase inhibitor, P276-00. Mol Cancer Ther 6: 918-925, 2007.

58. Giordano A, Rossi A, Romano G and Bagella L: Tumor suppressor $\mathrm{pRb} 2 / \mathrm{p} 130$ gene and its derived product Spa310 spacer domain as perspective candidates for cancer therapy. J Cell Physiol 213: 403-406, 2007.

59. De Azevedo WF, Leclerc S, Meijer L, Havlicek L, Strnad M and Kim SH: Inhibition of cyclin-dependent kinases by purine analogues: Crystal structure of human cdk2 complexed with roscovitine. Eur J Biochem 243: 518-526, 1997. 
60. Lee B, Sandhu S and McArthur G: Cell cycle control as a promising target in melanoma. Curr Opin Oncol 27: 141-150, 2015.

61. Dange Y, Bhinge S and Salunkhe V: Optimization and validation of RP-HPLC method for simultaneous estimation of palbociclib and letrozole. Toxicol Mech Methods 1-8, 2017.

62. Guha M: Cyclin-dependent kinase inhibitors move into Phase III Nat Rev Drug Discov 11: 892-894, 2012.

63. Cardoso F, Bischoff J, Brain E, Zotano ÁG, Lück HJ Tjan-Heijnen VC, Tanner M and Aapro M: A review of the treatment of endocrine responsive metastatic breast cancer in postmenopausal women. Cancer Treat Rev 39: 457-465, 2013.

64. Sammons SL, Topping DL and Blackwell KL: HR ${ }^{+}$, HER2 advanced breast cancer and CDK4/6 inhibitors: mode of action, clinical activity, and safety profiles. Current Cancer Drug Targets 17: 637-649, 2017.

65. Costa R, Costa RB, Talamantes SM, Helenowski I, Peterson J, Kaplan J, Carneiro BA, Giles FJ and Gradishar WJ: Meta-analysis of selected toxicity endpoints of CDK4/6 inhibitors: Palbociclib and ribociclib. Breast 35: 1-7, 2017.

66. Iwata H, Im SA, Masuda N, Im YH, Inoue K, Rai Y, Nakamura R Kim JH, Hoffman JT, Zhang K, et al: PALOMA-3: Phase III trial of fulvestrant with or without palbociclib in premenopausal and postmenopausal women with hormone receptor-positive, human epidermal growth factor receptor 2-negative metastatic breast cancer that progressed on prior endocrine therapy-safety and efficacy in Asian patients. J Global Oncol 3: 289-303, 2017.

67. Loibl S, Turner NC, Ro J, Cristofanilli M, Iwata H, Im SA, Masuda N,Loi S, André F, Harbeck N, et al: Palbociclib combined with fulvestrant in premenopausal women with advanced breast cancer and prior progression on endocrine therapy: PALOMA-3 Results. Oncologist 22: 1028-1038, 2017.

68. Schwartz GK, LoRusso PM, Dickson MA, Randolph SS, Shaik MN, Wilner KD, Courtney R and O'Dwyer PJ: Phase I study of PD 0332991, a cyclin-dependent kinase inhibitor, administered in 3-week cycles (Schedule 2/1). Br J Cancer 104: $1862-1868,2011$.

69. Fribbens C, OLeary B, Kilburn L, Hrebien S, Garcia-Murillas I, Beaney M, Cristofanilli M, Andre F, Loi S, Loibl S, et al: Plasma ESR 1 mutations and the treatment of estrogen receptor-positive advanced breast cancer. J Clin Oncol 34: 2961-2968, 2016.

70. Gelsomino L, Gu G, Rechoum Y, Beyer AR, Pejerrey SM, Tsimelzon A, Wang T, Huffman K, Ludlow A, Andò S and Fuqua SAW: ESR1 mutations affect anti-proliferative responses to tamoxifen through enhanced cross-talk with IGF signaling. Breast Cancer Res Treat 157: 253-265, 2016.

71. Kuehl WM and Bergsagel PL: Molecular pathogenesis of multiple myeloma and its premalignant precursor. J Clin Invest 122: 3456-3463, 2012.

72. Ocio EM, Mitsiades CS, Orlowski RZ and Anderson KC: Future agents and treatment directions in multiple myeloma. Expert Rev Hematol 7: 127-141, 2014.

73. Castelli R, Gualtierotti R, Orofino N, Losurdo A, Gandolfi S and Cugno M: Current and emerging treatment options for patients with relapsed myeloma. Clin Med Insights Oncol 7: 209-219, 2013.

74. Niesvizky R, Badros AZ, Costa LJ, Ely SA, Singhal SB, Stadtmauer EA, Haideri NA, Yacoub A, Hess G, Lentzsch S, et al: Phase 1/2 study of cyclin-dependent kinase (CDK)4/6 inhibitor palbociclib (PD-0332991) with bortezomib and dexamethasone in relapsed/refractory multiple myeloma. Leuk Lymphoma 56: 3320-3328, 2015

75. Richardson PG, Barlogie B, Berenson J, Singhal S, Jagannath S, Irwin D, Rajkumar SV, Srkalovic G, Alsina M, Alexanian R, et al: A phase 2 study of bortezomib in relapsed, refractory myeloma. N Engl J Med 348: 2609-2617, 2003.
76. Perumal D, Kuo PY, Leshchenko VV, Jiang Z, Divakar SK, Cho HJ, Chari A, Brody J, Reddy MV, Zhang W, et al: Dual targeting of CDK4 and ARK5 using a novel kinase inhibitor ON123300 exerts potent anticancer activity against multiple myeloma. Cancer Res 76: 1225-1236, 2016.

77. Liu L, Ulbrich J, Müller J, Wüstefeld T, Aeberhard L, Kress TR, Muthalagu N, Rycak L, Rudalska R, Moll R, et al: Deregulated MYC expression induces dependence upon AMPK-related kinase 5. Nature 483: 608-612, 2012.

78. Sequist LV, Yang JC, Yamamoto N, O'Byrne K, Hirsh V, Mok T, Geater SL, Orlov S, Tsai CM, Boyer M, et al: Phase III study of afatinib or cisplatin plus pemetrexed in patients with metastatic lung adenocarcinoma with EGFR mutations. J Clin Oncol 31: 3327-3334, 2013.

79. Liu M, Xu S, Wang Y, Li Y, Li Y, Zhang H, Liu H and Chen J: PD 0332991, a selective cyclin D kinase 4/6 inhibitor, sensitizes lung cancer cells to treatment with epidermal growth factor receptor tyrosine kinase inhibitors. Oncotarget 7: 84951-84964, 2016.

80. Shaw AT, Winslow MM, Magendantz M, Ouyang C, Dowdle J, Subramanian A, Lewis TA, Maglathin RL, Tolliday N and Jacks T: Selective killing of K-ras mutant cancer cells by small molecule inducers of oxidative stress. Proc Natl Acad Sci USA 108: 8773-8778, 2011.

81. Montagut $\mathrm{C}$ and Settleman J: Targeting the RAF-MEK-ERK pathway in cancer therapy. Cancer Lett 283: 125-134, 2009.

82. Tao Z, Le Blanc JM, Wang C, Zhan T, Zhuang H, Wang P, Yuan Z and Lu B: Coadministration of trametinib and palbociclib radiosensitizes KRAS-mutant non-small cell lung cancers in vitro and in vivo. Clin Cancer Res 22: 122-133, 2016.

83. Cancer Genome Atlas Research Network: Comprehensive genomic characterization of squamous cell lung cancers. Nature 489: 519-525, 2012.

84. Chikara S, Lindsey K, Dhillon H, Mamidi S, Kittilson J, Christofidou-Solomidou M and Reindl KM: Enterolactone induces G1-phase cell cycle arrest in nonsmall cell lung cancer cells by downregulating cyclins and cyclin-dependent kinases. Nutr Cancer 69: 652-662, 2017.

85. Chen DH and Zhang XS: Targeted therapy: Resistance and re-sensitization. Chin J Cancer 34: 496-501, 2015.

86. Lee JE, Park HS, Lee D, Yoo G, Kim T, Jeon H, Yeo MK, Lee CS, Moon JY, Jung SS, et al: Hippo pathway effector YAP inhibition restores the sensitivity of EGFR-TKI in lung adenocarcinoma having primary or acquired EGFR-TKI resistance. Biochem Biophys Res Commun 474: 154-160, 2016.

87. Cross DA, Ashton SE, Ghiorghiu S, Eberlein C, Nebhan CA, Spitzler PJ, Orme JP, Finlay MR, Ward RA, Mellor MJ, et al: AZD9291, an irreversible EGFR TKI, overcomes T790Mmediated resistance to EGFR inhibitors in lung cancer. Cancer Discov 4: 1046-1061, 2014

88. Luque-Cabal M, García-Teijido P, Fernández-Pérez Y, Sánchez-Lorenzo L and Palacio-Vázquez I: Mechanisms behind the resistance to trastuzumab in her2-amplified breast cancer and strategies to overcome it. Clin Med Insights Oncol 10 (Suppl 1): S21-S30, 2016

89. Teh JL, Purwin TJ, Greenawalt EJ, Chervoneva I, Goldberg A, Davies MA and Aplin AE: An in vivo reporter to quantitatively and temporally analyze the effects of CDK4/6 inhibitor-based therapies in melanoma. Cancer Res 76: 5455-5466, 2016.

90. Kwiatkowski N, Zhang T, Rahl PB, Abraham BJ, Reddy J, Ficarro SB, Dastur A, Amzallag A, Ramaswamy S, Tesar B, et al: Targeting transcription regulation in cancer with a covalent CDK7 inhibitor. Nature 511: 616-620, 2014. 